Article

\title{
The Sensory Quality Improvement of Citrus Wine through Co-Fermentations with Selected Non-Saccharomyces Yeast Strains and Saccharomyces cerevisiae
}

\author{
Lanlan Hu ${ }^{1}$, Rui Liu ${ }^{1}$, Xiaohong Wang ${ }^{1,2}$ and Xiuyan Zhang ${ }^{1,2, *}$ \\ 1 College of Food Science and Technology, Huazhong Agricultural University, Wuhan 430070, China; \\ Hulanlan@webmail.hzau.edu.cn (L.H.); Liurui@webmail.hzau.edu.cn (R.L.); \\ Wxh@webmail.hzau.edu.cn (X.W.) \\ 2 Hubei International Scientific and Technological Cooperation Base of Traditional Fermented Foods, \\ College of Food Science and Technology, Huazhong Agricultural University, Wuhan 430070, China \\ * Correspondence: xiuyanzhang73@mail.hzau.edu.cn; Tel./Fax: +86-278-7282-927
}

Received: 21 December 2019; Accepted: 18 February 2020; Published: 26 February 2020

\begin{abstract}
Co-fermentation of selected non-Saccharomyces yeast strain with Saccharomyces cerevisiae is regarded as a promising approach to improve the sensory quality of fruit wine. To evaluate the effects of co-fermentations between the selected non-Saccharomyces yeast strains (Hanseniaspora opuntiae, Hanseniaspora uvarum and Torulaspora delbrueckii) and S. cerevisiae on the sensory quality of citrus wine, the fermentation processes, the chemical compositions, and the sensory evaluations of citrus wines were analyzed. Compared with those of S. cerevisiae fermentation, co-fermentations produced high sensory qualities, and S. cerevisiae/H. opuntiae co-fermentation had the best sensory quality followed by Sc-Hu and Sc-Td co-fermentations. Additionally, all the co-fermentations had a lower amount of ethanol and total acidity, higher $\mathrm{pH}$ value, and higher content of volatile aroma compounds, especially the content of higher alcohol and ester compounds, than those of S. cerevisiae fermentation. Therefore, co-fermentations of the non-Saccharomyces yeast strains and S. cerevisiae could be employed to improve the sensory quality of citrus wines. These results would provide not only methods to improve the sensory quality of citrus wine, but also a valuable reference for the selection of non-Saccharomyces yeast strains for fruit wine fermentation.
\end{abstract}

Keywords: Citrus wine; Non-Saccharomyces yeast strains; Co-fermentation; Sensory quality

\section{Introduction}

Citrus is one of the most abundant fruit crops in China, with a production of 8.56 million tons, accounting for $11.8 \%$ of the global production in 2017 (FAO, 2017). Mandarin fruit cv. Ponkan (Citrus reticulata Blanco cv. Ponkan) is widely cultivated in Asian countries for its high quality [1]. Ponkan has a thin skin, and the quality of the fruit during storage at room temperature is highly prone to deterioration and decay over time. Improving storage performance and reducing fruit decay during storage and transportation are major issues for the citrus industry [2,3]. In addition to being consumed as fresh fruit, citrus can also be processed into citrus wine to extend its shelf life and increase its added value [4]. However, the insufficient research and development of fermented citrus wine, as well as the poor flavor and quality of citrus wine, decreased its competitiveness on the fruit wine market [5].

Yeasts are primarily responsible for the alcoholic fermentation of fruit juice. Industrial fruit wine is usually fermented by using commercial Saccharomyces cerevisiae with the advantages of the controllable processes and stable quality products, but its sensory quality is inferior to those of successful 
spontaneous fermentation [6]. Nowadays, more and more non-Saccharomyces yeast strains, such as Torulaspora delbrueckii, Hanseniaspora uvarum, Hanseniaspora vineae, Metschnikowia pulcherrima, Lachancea thermotolerans, Pichia kluyveri, Pichia fermentans, Candida zemplinina, Candida stellate, Zygotorulaspora florentina and Schizosaccharomyces pombe, were employed to ferment fruit wine with S. cerevisiae to improve the sensory quality of fruit wine by producing low content of volatile acids, high content of aroma compounds and glycerol [7-15]. However, some non-Saccharomyces yeast strains might produce undesirable metabolites during fruit wine fermentation, such as acetic acid, aldehyde, volatile phenols, and acetoin etc. [16-18], while others might not grow normally under the harsh fermentation environments (poor nutrition, low $\mathrm{pH}$ and temperature, high content of ethanol and $\mathrm{SO}_{2}$, competition from other microorganisms) $[19,20]$. All aspects generally considered for non-Saccharomyces in grape musts/wines in the current subject research [20-23]. Therefore, it is important to study the effects of non-Saccharomyces yeast strains on the fermentation process and the sensory quality of non-grape fruit wine. Our research group reported that the pure fermentation of Hanseniaspora opuntiae, H. uvarum, or T. delbrueckii displayed positive effects on the sensory quality of citrus wine, while they also had an incomplete ethanol fermentation [24]. Therefore, these non-Saccharomyces yeast strains can be used to ferment citrus wine with $S$. cerevisiae which had outstanding sugar consumption ability [6]. However, it is still unknown whether co-fermentation of these three non-Saccharomyces yeast strains with $S$. cerevisiae could improve the sensory quality of citrus wine with complete ethanol fermentation or not.

To investigate the effects of co-fermentations between the selected non-Saccharomyces yeast strains and S. cerevisiae on the citrus wine, the fermentation processes, the chemical compositions and sensory evaluations of citrus wines were analyzed. Research results would provide methods to improve the sensory quality of citrus wine and provide references for the selection of non-Saccharomyces yeast strains for fruit wine fermentation.

\section{Materials and Methods}

\subsection{Citrus Juice Preparation}

The citrus fruit (Ponkan) was harvested from Wuhan citrus plantation (Wuhan city, Hubei province, China) in 2016. The citrus juice ( $\mathrm{pH} 3.36,11$ Brix of total soluble solids, $60.37 \mathrm{~g} / \mathrm{L}$ of initial sugar, $3.8 \mathrm{~g} / \mathrm{L}$ of total acidity) was prepared by peeling, crushing and squeezing from fresh citrus, and then pasteurizing for $15 \mathrm{~min}$ at $104{ }^{\circ} \mathrm{C}$.

\subsection{Yeast Strains and Media}

Hanseniaspora opuntiae, Hanseniaspora uvarum and Torulaspora delbrueckii were isolated from spontaneously fermented citrus wine and orangeries [5]. Saccharomyces cerevisiae was obtained from the Laffort group (Actiflore Cerevisiae, Laffort Co., Bordeaux, France).

Yeasts extract peptone dextrose (YEPD) medium (10.0 g/L yeasts extract, $20.0 \mathrm{~g} / \mathrm{L}$ peptone, and $20.0 \mathrm{~g} / \mathrm{L}$ dextrose) was employed to culture the starters.

Wallerstein laboratory nutrient agar (WL) medium $\left(50.0 \mathrm{~g} / \mathrm{L}\right.$ dextrose, $0.125 \mathrm{~g} / \mathrm{L} \mathrm{MgSO}_{4}, 5.0 \mathrm{~g} / \mathrm{L}$ tryptone, $0.022 \mathrm{~g} / \mathrm{L}$ bromocresol green, $4.0 \mathrm{~g} / \mathrm{L}$ yeasts extract, $0.0025 \mathrm{~g} / \mathrm{L} \mathrm{FeCl}{ }_{3}, 0.55 \mathrm{~g} / \mathrm{L} \mathrm{KH}_{2} \mathrm{PO}_{4}$, $0.0025 \mathrm{~g} / \mathrm{L} \mathrm{MnSO}_{4}, 0.425 \mathrm{~g} / \mathrm{L} \mathrm{KCl}, 15.0 \mathrm{~g} / \mathrm{L}$ agar and $\left.0.125 \mathrm{~g} / \mathrm{L} \mathrm{CaCl}_{2}, \mathrm{pH} 5.5\right)$ was used to differentiate S. cerevisiae from non-Saccharomyces yeast strains according to the colony morphology [25].

Lysine agar (LYS) medium $\left(10.0 \mathrm{~g} / \mathrm{L}\right.$ dextrose, $5.0 \mathrm{~g} / \mathrm{L}$ lysine, $0.1 \mathrm{~g} / \mathrm{L} \mathrm{KH}_{2} \mathrm{PO}_{4}, 0.1 \mathrm{~g} / \mathrm{L} \mathrm{MgSO}{ }_{4}$, complex vitamin $0.1 \mathrm{~g} / \mathrm{L}$ and agar $15.0 \mathrm{~g} / \mathrm{L}, \mathrm{pH} 4.8$ ) was used to count the non-Saccharomyces yeast strain cells during co-fermentations.

\subsection{Laboratory-Scale Fermentation of Citrus Wine}

After adjusted to $210 \mathrm{~g} / \mathrm{L}$ sugar and $50 \mathrm{mg} / \mathrm{L} \mathrm{SO}_{2}$ by exogenous addition of $104.741 \mathrm{~g}$ sucrose and $0.566 \mathrm{~mL}$ saturated sulfurous acid solution, respectively, $700 \mathrm{~mL}$ citrus juice was fermented with 
starters of S. cerevisiae/H. uvarum (Sc-Hu), S. cerevisiae/T. delbrueckii (Sc-Td) or S. cerevisiae/H. opuntiae (Sc-Hop) in $1.0 \mathrm{~L}$ sterile bottles at $25^{\circ} \mathrm{C}$. The co-fermentations were performed with co-cultures of $10^{7} \mathrm{CFU} / \mathrm{mL}$ non-Saccharomyces yeast strain and $10^{6} \mathrm{CFU} / \mathrm{mL}$ S. cerevisiae with sequence inoculation strategy. The sequence inoculation strategy meant that $S$. cerevisiae was inoculated into citrus juice $24 \mathrm{~h}$ later than H. opuntiae and T. delbrueckii, or $72 \mathrm{~h}$ later than H. uvarum. Pure fermentation of S. cerevisiae with $10^{6} \mathrm{CFU} / \mathrm{mL}$ inoculation was used as a control. The fermentation process of citrus wine was monitored by analyzing the residual sugar concentration and yeast cell counts daily. Residual sugar concentration of citrus wine was assessed by dinitrosalicylic acid (DNS) method according to the International Organization of the Vine and Wine (OIV, 2005). Yeast cell count was determined by successive dilution method on the WL medium and LYS medium. All reagents were obtained from Sigma-Aldrich (Sigma-Aldrich, Shanghai, China).

\subsection{Physicochemical Analysis of Citrus Wine}

The content of residual sugar, total acidity (expressed as $\mathrm{g} / \mathrm{L}$ of malic acid) and volatile acid (expressed as $\mathrm{g} / \mathrm{L}$ of acetic acid) of citrus wine were analyzed by the International Organization of the Vine and Wine (OIV, 2005). Bromothymol blue titration method was used to analyze the total acidity of citrus wine. Distillation and titration method was applied to evaluate the volatile acid of citrus wine. Rapid oxidation of potassium permanganate method was employed to detect the alcohol content of citrus wine. The $\mathrm{pH}$ value of citrus wine was determined by $\mathrm{pH}$ meter (Mettler-Toledo, Shanghai, China). All experiments were determined in triplicate.

\subsection{HS-SPME/GC-MS Analysis of Volatile Aroma Compounds}

The volatile aroma compounds were extracted by headspace solid-phase microextraction (HS-SPME) method with a 50/30 $\mu$ m divinylbenzene/carboxen/polydimethylsiloxane (DVB/CAR/PDMS) fiber (Supelco, Bellefonte PA, USA). The Agilent 6890N gas chromatography (Agilent 6890N, Agilent Technologies Inc., Shanghai, China) on an HP-5 capillary column (30 m $\times 0.32 \mathrm{~mm} \times 0.25 \mu \mathrm{m})$ coupled to an Agilent 5975B mass spectrometer was used to analyze the extracted volatile aroma compounds. The extraction, analysis, and identification of volatile aroma compounds were conducted as described by $\mathrm{Hu}$ et al. [24]. The odor active value (OAV), calculated as the ratio between the concentration of flavor compound to its odor threshold (OT), was used to obtain odor patterns. Volatile aroma compounds with $\mathrm{OAV} \geq 1$ were considered as odor-active compounds [26].

\subsection{Sensory Evaluation of Citrus Wine}

The sensory evaluation of citrus wine was conducted by a trained panel consisting of nine panelists (five females and four males) from Huazhong Agricultural University. The sensory evaluation of citrus wine was performed as described by [24].

\subsection{Statistical Analyses}

One-way ANOVA and Duncan test of all indicated significant differences were conducted by SPSS 19.0 (SPSS Inc., Chicago, IL, USA). Principal component analysis (PCA) was performed to identify the most influential volatile aroma compounds in different fermentations by SIMCA-P 14.1 (Umetrics AB, Umea, Sweden). Hierarchical cluster analysis and heat map visualization of volatile aroma compounds with the Z-score standardization in different fermentations were analyzed by MultiExperiment Viewer 4.9.0 (TIGR, America).

\section{Results and Discussions}

\subsection{Growth Kinetics and Sugar Consumption Kinetics of Yeast Strains during Fermentations}

As charted in Figure 1, these non-Saccharomyces yeast strains shortly adapted to the fermentation environment, then grew normally within 4-6 days and reached their maximum biomass of $1.0 \times$ 
$10^{8} \mathrm{CFU} / \mathrm{mL}$. However, the growth of $H$. uvarum was immediately inhibited by $S$. cerevisiae with sharp decrease of biomass during fermentation (Figure 1A). The growth inhibition phenomenon of non-Saccharomyces yeast strains were also reported in other studies [27,28]. Additionally, the early inoculation of these non-Saccharomyces yeast strains negligibly affected the maximum biomass of S. cerevisiae $\left(1.4 \times 10^{8}-1.9 \times 10^{8} \mathrm{CFU} / \mathrm{mL}\right)$ in co-fermentations compared with that of pure S. cerevisiae fermentation $\left(2.3 \times 10^{8} \mathrm{CFU} / \mathrm{mL}\right)$ (Figure 1A-D). These results indicated the selected non-Saccharomyces yeast strains and $S$. cerevisiae could grow normally during their co-fermentation with the exception of $H$. uvarum which was inhibited by S. cerevisiae. The inhibition of non-Saccharomyces yeast strains was probably ascribed to the fierce nutrients competition or killer factors from S. cerevisiae [29].
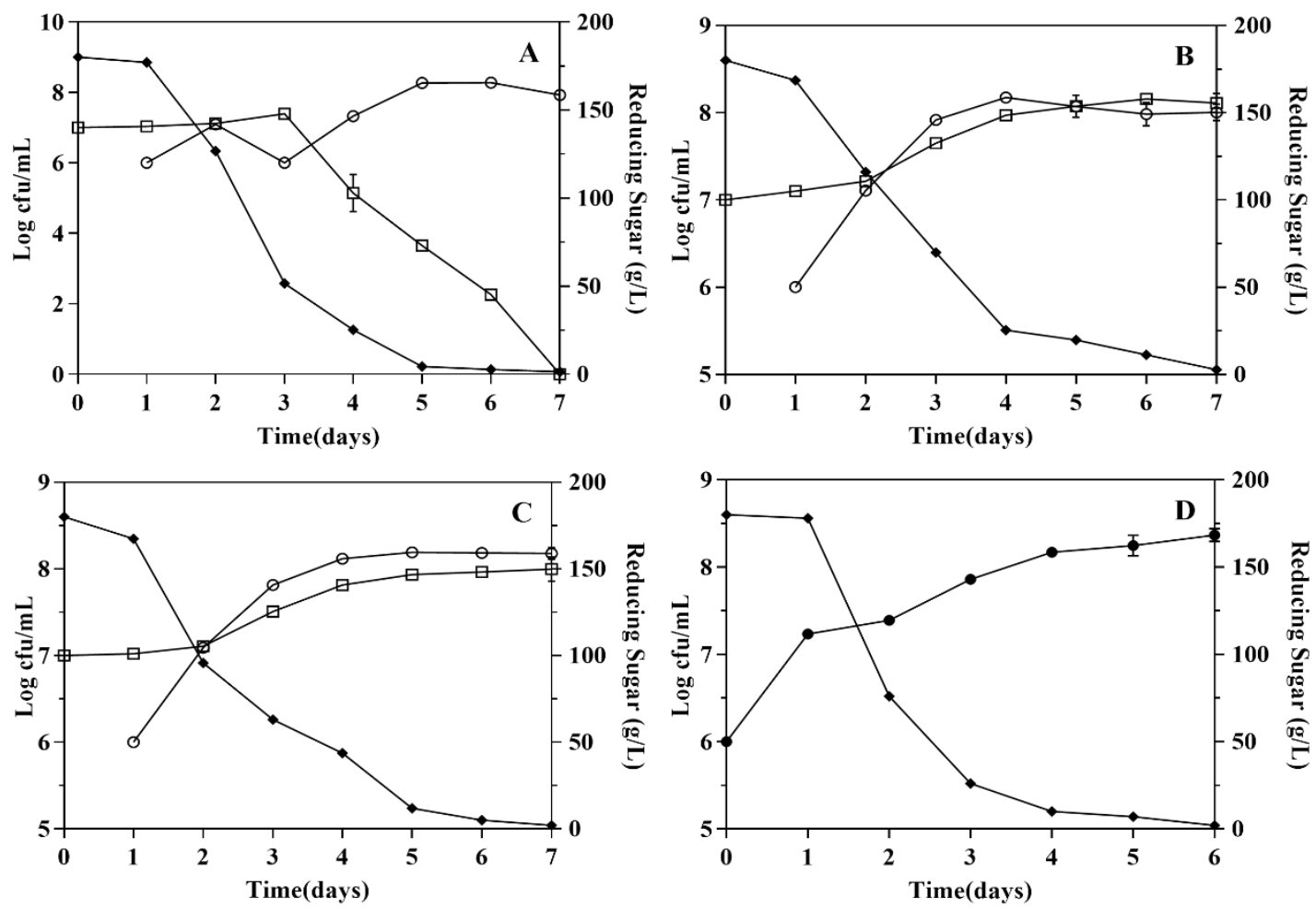

Figure 1. Growth kinetics and sugar consumption kinetics of yeast strains during fermentations. (A, B and $\mathbf{C}$ are co-fermentation with S. cerevisiae, and D is pure culture). A. H. uvarum; B. T. delbrueckii; C. H. opuntiae; D. S. cerevisiae. - $\square$ - Growth kinetics of non-Saccharomyces in co-fermentations - - Sugar consumption kinetics. -o- Growth kinetics of S. cerevisiae in co-fermentations - $\bullet$ - Growth kinetics of S. cerevisiae in pure fermentation

\subsection{Physicochemical Parameters of Citrus Wine}

As presented in Table 1, co-fermentations of non-Saccharomyces yeast strains and S. cerevisiae contained lower concentrations of ethanol $(9.74 \%-10.24 \%)$ and total acidity $(7.68-8.63 \mathrm{~g} / \mathrm{L})$ than pure S. cerevisiae fermentation did $(11.29 \%$ and $9.44 \mathrm{~g} / \mathrm{L})$. The Sc-Hu co-fermentation possessed a lower concentration of residual sugar $(1.38 \mathrm{~g} / \mathrm{L})$, while others contained a higher level of residual sugar $(2.03-2.81 \mathrm{~g} / \mathrm{L})$ than pure $S$. cerevisiae fermentation did $(2.03 \mathrm{~g} / \mathrm{L})$, which might be caused by different sugar consumption abilities of these yeast strains $[30,31]$. The $\mathrm{pH}$ value of co-fermentations (3.37-3.47) increased compared with that of pure S. cerevisiae fermentation (3.35), which was also found in co-fermented bilberry wine [32]. Additionally, the volatile acid concentrations in co-fermentations $(0.11-0.12 \mathrm{~g} / \mathrm{L})$ with the exception of Sc-Td co-fermentation $(0.15 \mathrm{~g} / \mathrm{L})$ displayed insignificant difference from that of pure $S$. cerevisiae fermentation $(0.11 \mathrm{~g} / \mathrm{L})$, while other researchers reported that co-fermentations had a lower content of volatile acid than pure S. cerevisiae fermentation 
had $[8,33]$. The different research results in volatile acid content might be caused by different fruit juice, fermentation strategies or starters. These results indicated these co-fermentations produced citrus wine with lower content of ethanol and total acidity, higher $\mathrm{pH}$ value and with no significant difference in volatile acid concentration.

Table 1. Physicochemical parameters of citrus wines (Means \pm SD).

\begin{tabular}{cccccc}
\hline Fermentations & $\begin{array}{c}\text { Residual Sugar } \\
(\mathbf{g} / \mathbf{L})\end{array}$ & $\begin{array}{c}\text { Ethanol } \\
(\mathbf{\%}, \mathbf{v} / \mathbf{v})\end{array}$ & $\begin{array}{c}\text { Total Acidity } \\
(\mathbf{g} / \mathbf{L})\end{array}$ & $\begin{array}{c}\text { Volatile Acid } \mathbf{b}^{\mathbf{b}} \\
(\mathbf{g} / \mathbf{L})\end{array}$ & $\mathbf{p H}$ \\
\hline Sc-Hu & $1.38 \pm 0.08^{* *}$ & $10.24 \pm 0.08^{*}$ & $7.68 \pm 0.01^{* *}$ & $0.12 \pm 0.00$ & $3.45 \pm 0.00^{* *}$ \\
Sc-Td & $2.81 \pm 0.13^{* *}$ & $9.74 \pm 0.12^{* *}$ & $8.63 \pm 0.06^{* *}$ & $0.15 \pm 0.01^{* *}$ & $3.47 \pm 0.01^{* *}$ \\
Sc-Hop & $2.03 \pm 0.08$ & $9.83 \pm 0.49^{*}$ & $8.52 \pm 0.02^{* *}$ & $0.11 \pm 0.02$ & $3.37 \pm 0.06$ \\
Sc & $2.03 \pm 0.13$ & $11.29 \pm 0.26$ & $9.44 \pm 0.07$ & $0.11 \pm 0.01$ & $3.35 \pm 0.00$ \\
\hline
\end{tabular}

Data show the mean value of triplicate, and the significant differences in each row are respect to the control Sc.

${ }^{a}$ Expressed as $\mathrm{g} / \mathrm{L}$ of malic acid; ${ }^{b}$ Expressed as $\mathrm{g} / \mathrm{L}$ of acetic acid ${ }^{* *} p<0.01 ;{ }^{*} p<0.05$. Sc-Hu, S. cerevisiae/H. uvarum co-fermentation; Sc-Td, S. cerevisiae/T. delbrueckii co-fermentation; Sc-Hop, S. cerevisiae/H. opuntiae co-fermentation; Sc, S. cerevisiae fermentation.

\subsection{Volatile Aroma Compounds in Citrus Wines}

Forty-eight kinds of volatile aroma compounds in citrus wines, including 8 kinds of higher alcohols, 6 kinds of fatty acids, 24 kinds of esters and 10 kinds of other compounds, were detected. Compared with the $S$. cerevisiae fermentation, co-fermentations of these non-Saccharomyces yeast strains and S. cerevisiae produced higher content of volatile aroma compounds, and Sc-Td co-fermentation produced the maximum amount of volatile aroma compounds $(819.46 \mathrm{mg} / \mathrm{L})$, followed by Sc-Hop (689.32 mg/L), Sc-Hu (519.97 mg/L) and Sc fermentations (187.58 mg/L). Moreover, co-fermentations produced higher content of higher alcohol, acetate and terpene, and lower content of volatile fatty acids with the exception of Sc-Td fermentation (Table 2).

Table 2. Volatile aroma compounds in citrus wines (Means $\pm \mathrm{SD}, \mathrm{mg} / \mathrm{L}$ ).

\begin{tabular}{|c|c|c|c|c|c|}
\hline Number & Compounds & $\mathrm{Sc}-\mathrm{Hu}$ & Sc-Td & Sc-Hop & Sc \\
\hline \multicolumn{6}{|c|}{ Higher alcohols } \\
\hline 1 & 1-Pentanol & $49.61 \pm 0.39^{a}$ & $309.54 \pm 1.47^{b}$ & $103.00 \pm 1.00^{c}$ & $53.95 \pm 0.29^{d}$ \\
\hline 3 & Ribitol & - & - & - & $0.81 \pm 0.02$ \\
\hline 4 & 3-Methyl-1-hexanol & $0.76 \pm 0.04$ & - & - & - \\
\hline 5 & 4-Methylphenylpropanol & $0.06 \pm 0.01^{\mathrm{a}}$ & - & $0.21 \pm 0.02^{b}$ & - \\
\hline 7 & Phenylethanol & $183.00 \pm 3.00^{\mathrm{a}}$ & $270.99 \pm 3.01^{b}$ & $306.33 \pm 4.51^{c}$ & $33.21 \pm 0.04^{d}$ \\
\hline 8 & Isolongifolan-8-ol & $0.02 \pm 0.01^{\mathrm{a}}$ & $0.31 \pm 0.03^{b}$ & - & - \\
\hline \multicolumn{6}{|c|}{$\begin{array}{c}\text { subtotal } \\
\text { Fatty acids }\end{array}$} \\
\hline 1 & Dodecanoic acid & - & - & - & $0.04 \pm 0.01$ \\
\hline 6 & 2,4-Dimethyl-benzoic acid & $0.06 \pm 0.01$ & - & - & - \\
\hline \multicolumn{6}{|c|}{$\begin{array}{l}\text { subtotal } \\
\text { Acetates }\end{array}$} \\
\hline 1 & Ethyl acetate & $153.50 \pm 3.50^{\mathrm{a}}$ & $32.04 \pm 0.74^{b}$ & $81.64 \pm 0.66^{c}$ & $4.36 \pm 0.10^{d}$ \\
\hline 2 & Isoamyl acetate & $45.41 \pm 0.81^{\mathrm{a}}$ & $47.60 \pm 0.40^{b}$ & $39.53 \pm 0.53^{c}$ & $18.51 \pm 0.49^{\mathrm{d}}$ \\
\hline 3 & Amyl acetate & $0.19 \pm 0.01$ & - & - & - \\
\hline 4 & Phenethyl acetate & $37.46 \pm 0.76^{a}$ & $46.59 \pm 0.51^{b}$ & $78.55 \pm 0.45^{\mathrm{c}}$ & $6.94 \pm 0.06^{\mathrm{d}}$ \\
\hline \multicolumn{6}{|c|}{ Ethyl esters } \\
\hline 1 & Ethyl butyrate & $0.34 \pm 0.04^{\mathrm{a}}$ & $4.93 \pm 0.02^{b}$ & $0.57 \pm 0.02^{c}$ & $0.91 \pm 0.02^{d}$ \\
\hline
\end{tabular}


Table 2. Cont.

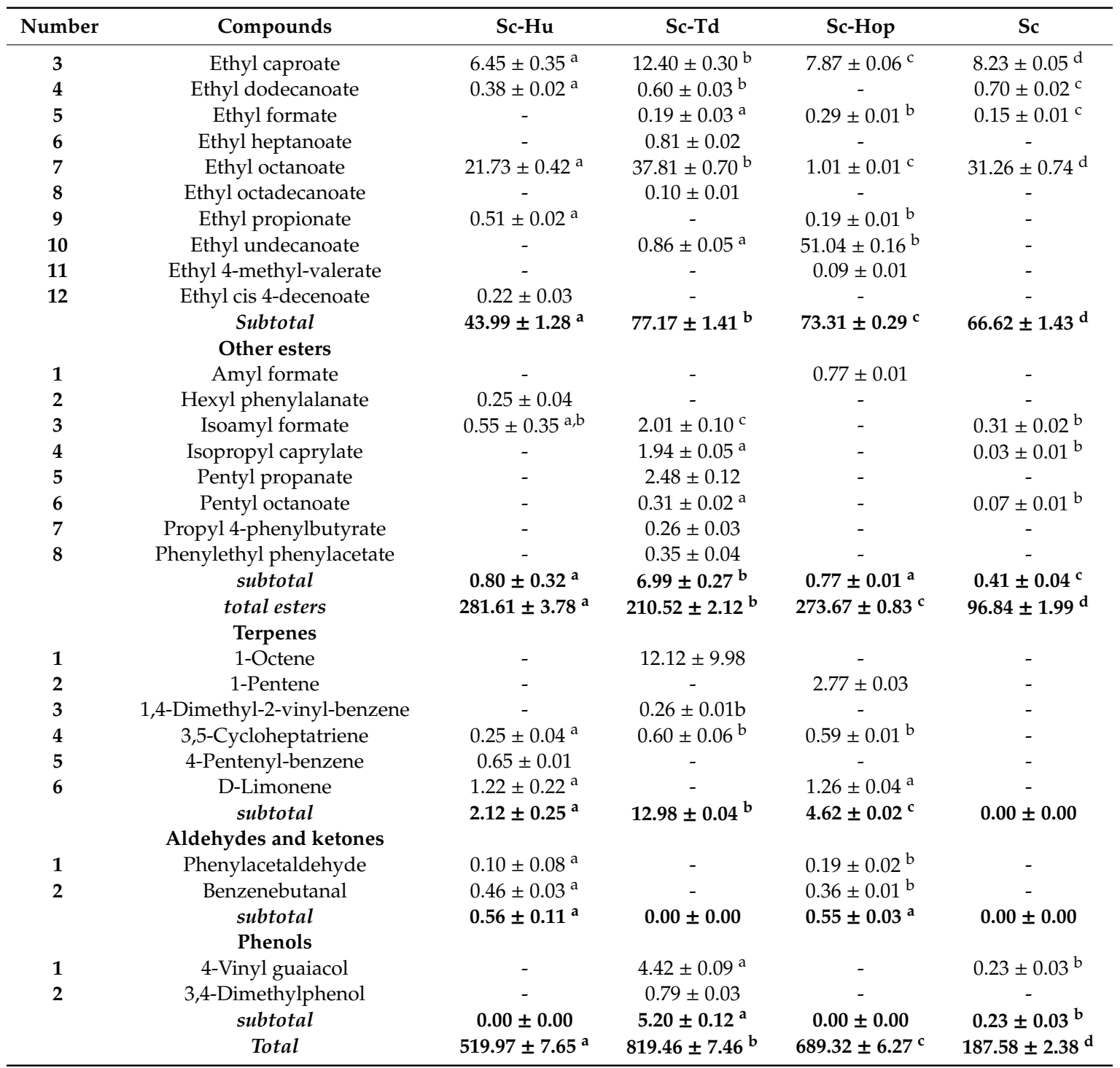

Data show the mean value of triplicate, and "-" presented no detection; Different letters in each row presented statistically significant differences among citrus wines at $p<0.05$. Sc-Hu, S. cerevisiae/H. uvarum co-fermentation; Sc-Td, S. cerevisiae/T. delbrueckii co-fermentation; Sc-Hop, S. cerevisiae/H. opuntiae co-fermentation; Sc, S. cerevisiae fermentation. Bold value indicated the subtotal value of the type of aroma compounds

\subsubsection{Higher Alcohols}

Higher alcohols contributed positively to the "fresh fruity", "vegetal" notes, and aroma complexity in young red wine [34]. Higher alcohols could react with organic acids to form esters with a pleasant flavor, while excessive levels ( $\geq 500 \mathrm{mg} / \mathrm{L}$ ) may lead to unpleasant flavor in alcohol beverage [35]. As tabulated in Tables 2 and 3, co-fermentations produced higher concentrations of higher alcohols $(235.52 \mathrm{mg} / \mathrm{L}-580.72 \mathrm{mg} / \mathrm{L})$ than that of pure S. cerevisiae fermentation did $(87.97 \mathrm{mg} / \mathrm{L})$. The Sc-Td co-fermentation produced the maximum concentration of higher alcohols $(580.72 \mathrm{mg} / \mathrm{L})$, followed by Sc-Hop $(410.48 \mathrm{mg} / \mathrm{L})$ and Sc-Hu $(235.52 \mathrm{mg} / \mathrm{L})$ fermentations. However, excessive concentration of higher alcohols (580.72 mg/L) in Sc-Td co-fermentation might result in undesirable flavor. Previous research also showed that $S$. cerevisiae/T. delbrueckii and S. cerevisiae/H. opuntiae co-fermentations generated large amounts of higher alcohols compared with pure S. cerevisiae fermentation did, while the differences in production of higher alcohols among different non-Saccharomyces strains were significant [36-38]. 
Among the detected alcohol groups, 1-pentanol and phenylethanol were the active odor compounds (OAV > 1), and the phenylethanol concentration in co-fermentations $(183.00 \mathrm{mg} / \mathrm{L}-306.33 \mathrm{mg} / \mathrm{L})$ was greatly higher than that of pure S. cerevisiae fermentation (33.21 mg/L), which was also reported by Sun et al. [33]. Phenylethanol usually presented on pleasant honey, floral aroma (rose petals), and spicy flavor $[39,40]$. Therefore, a higher amount of phenylethanol in co-fermentations would be positive to the flavor of citrus wines. Besides, the content of 1-pentanol with sweet and vanilla odor was higher in co-fermentation with the exceptions of Sc-Hu fermentation than that of pure S. cerevisiae fermentation did, which would strengthen the fruity and balsamic of citrus wine. These results revealed that co-fermentations of the non-Saccharomyces yeast strains and S. cerevisiae significantly contributed to the biosynthesis of higher alcohols, especially phenylethanol, and the higher alcohols production in fruit wine was determined by non-Saccharomyces yeast strain and the fermentation process.

Table 3. Volatile odor-active compounds $(\mathrm{OAV} \geq 1)$ in citrus wines.

\begin{tabular}{|c|c|c|c|c|c|c|}
\hline Compounds & Description & Threshold $^{\text {a }}$ & Sc-Hu & Sc-Td & Sc-Hop & Sc \\
\hline 1-Pentanol & Fruity, balsamic & $8[41]$ & 6.20 & 38.70 & 12.88 & 6.74 \\
\hline Phenylethanol & Honey, rose, spicy & $14[42]$ & 13.07 & 19.36 & 21.88 & 2.37 \\
\hline Ethyl acetate & $\begin{array}{c}\text { Pineapple, fruity, } \\
\text { solvent }\end{array}$ & $7.5[42]$ & 20.47 & 4.27 & 10.89 & 0.58 \\
\hline Isoamyl acetate & Banana, pear & $0.03[42]$ & 1513.67 & 1586.67 & 1317.67 & 617.00 \\
\hline Phenethyl acetate & Rose, honey, tobacco & $0.25[42]$ & 149.84 & 186.36 & 314.20 & 27.76 \\
\hline Ethyl butyrate & Strawberry & $0.02[43]$ & 17.00 & 246.25 & 28.25 & 45.25 \\
\hline Ethyl caproate & $\begin{array}{c}\text { Pineapple, fruity, } \\
\text { flowery }\end{array}$ & $0.014[44]$ & 460.71 & 885.71 & 561.79 & 587.86 \\
\hline Ethyl octanoate & Pineapple, pear, soapy & $0.002[42]$ & $10,862.50$ & $18,902.50$ & 505.00 & $15,627.50$ \\
\hline Ethyl caprate & Fruity, fresh & 0.28 & 51.39 & 68.29 & 43.75 & 90.64 \\
\hline Octanoic acid & Sweat, cheesy & $0.5[43]$ & 0.00 & 40.08 & 0.00 & 4.45 \\
\hline D-Limonene & Floral, green, citrus & $0.2[41]$ & 6.10 & 0.00 & 6.30 & 0.00 \\
\hline 1-Pentene & Honey, peach, sweat & $0.02678[45]$ & 0.00 & 0.00 & 103.44 & 0.00 \\
\hline Phenylacetaldehyde & Rose & $0.001[46]$ & 100.00 & 0.00 & 193.33 & 0.00 \\
\hline 4-Vinyl guaiacol & Coffee, beer, apple & $1.1[42]$ & 0.00 & 4.01 & 0.00 & 0.21 \\
\hline
\end{tabular}

\subsubsection{Fatty Acids}

As viewed in Tables 2 and 3, the Sc-Td co-fermentation produced higher concentration of fatty acids $(20.04 \mathrm{mg} / \mathrm{L})$ than S. cerevisiae fermentation did $(2.54 \mathrm{mg} / \mathrm{L})$, while other co-fermentations hardly produced fatty acids $(0.00 \mathrm{mg} / \mathrm{L}-0.16 \mathrm{mg} / \mathrm{L})$. Volatile fatty acids are essential precursors of ester productions that provide fruity aromas to wines [47], but excessive content of fatty acids ( $\geq 20 \mathrm{mg} / \mathrm{L}) \mathrm{in}$ Sc-Td co-fermentation might produce rancid flavor $[48,49]$. Octatonic acid was the only odor-active fatty acid and presented in Sc-Td co-fermentation $(\mathrm{OAV}=40.08)$ and pure S. cerevisiae fermentation $(\mathrm{OAV}=4.45)$. The high content of fatty acids, especially octatonic acid, in Sc-Td co-fermentation was inconsistent with previous report which indicated that co-fermentation of T. delbrueckii and S. cerevisiae greatly decreased the fatty acids concentration, especially octatonic acid [50], which might be caused by different fruit juice and fermentative process. These results indicated that co-fermentations of the selected non-Saccharomyces yeast strains and S. cerevisiae have no regular effects on the amount and the kinds of fatty acids in citrus wine, which might be determined by yeast strains, fruit juice, and fermentation process.

\subsubsection{Esters}

Esters compounds including acetates and ethyl esters are important aroma compounds with a positive contribution to the desired fruit aroma characters in wine [51]. The total ester concentrations 
in all the co-fermentations $(210.52 \mathrm{mg} / \mathrm{L}-281.61 \mathrm{mg} / \mathrm{L})$ with significant differences $(p<0.05)$ were higher than that of pure S. cerevisiae fermentation $(96.84 \mathrm{mg} / \mathrm{L})$ (Table 2), which was also found in bilberry wine co-fermented by T. delbrueckii and S. cerevisiae [39].

As for the acetates, all the co-fermentations also generated higher acetates amount than pure S. cerevisiae fermentation did, and Sc-Hu fermentation produced the maximum acetates content (236.82 mg/L), followed by Sc-Hop (199.59 mg/L) and Sc-Td fermentations (126.36 mg/L). Among the acetate compounds, ethyl acetate, isoamyl acetate, and phenethyl acetate were the odor active compounds $(\mathrm{OAV}>1)$ and greatly increased in all the co-fermentations compared with those of $S$. cerevisiae fermentation. Ethyl acetate may improve aroma complexity of wine at low level (approximately $50 \mathrm{mg} / \mathrm{L}$ ), but it is associated with negative sensory descriptors (nail polish and solvent etc.) at concentrations above $150 \mathrm{mg} / \mathrm{L}$. Therefore, the ethyl acetate concentration in Sc-Td and Sc-Hop fermentations $(32.04 \mathrm{mg} / \mathrm{L}$ and $81.64 \mathrm{mg} / \mathrm{L}$, respectively) would have positive effect on the flavor of citrus wine, while that in Sc-Hu fermentation $(153.50 \mathrm{mg} / \mathrm{L})$ might has negative effect on the sensory quality of citrus wine and should be evaluated through sensory evaluation furtherly. However, Mingorance-Cazorla et al. reported that $9.67 \mathrm{mg} / \mathrm{L}-163.18 \mathrm{mg} / \mathrm{L}$ ethyl acetate were also detected from citrus wine, and a little over threshold of ethyl acetate in citrus wine $(163.18 \mathrm{mg} / \mathrm{L})$ had no negative effect on its flavor [52]. Isoamyl acetate and phenethyl acetate are recognized as an important flavor compound in wine and contribute to the fruity notes of wine [39]. Moreira et al. [53] and Rojas et al. [54] also revealed that non-Saccharomyces yeast, such as H. uvarum, could increase the content of isoamyl acetate and the phenethyl acetate in wine. These results suggested that co-fermentations could improve the acetate content, especially the content of ethyl acetate, isoamyl acetate and phenethyl acetates in citrus wine compared with those of pure $S$. cerevisiae fermentation, which would be favorable to the flavor of citrus wine.

As for ethyl esters, Sc-Td and Sc-Hop fermentations displayed distinct advantage in ethyl esters producing (77.17 mg/L and $73.31 \mathrm{mg} / \mathrm{L}$, respectively), while Sc-Hu fermentation $(43.99 \mathrm{mg} / \mathrm{L})$ was slightly inferior to $S$. cerevisiae fermentation $(66.62 \mathrm{mg} / \mathrm{L})$ (Table 2). However, $\mathrm{Hu}$ et al. [55] reported co-culture of $H$. uvarum/S. cerevisiae produced more ethyl ester in wine than S. cerevisiae did. These differences in producing abilities of ethyl ester among different yeast strains might be caused by their different producing ability of organic acids, because the organic acids were the precursors of ethyl esters [56]. Among the ethyl ester compounds, ethyl caproate, ethyl octanoate and ethyl caprate were the odor active compounds, which were characterized by "pineapple, fruity and floral", "fruity, pineapple, pear and floral", and "fruity and fresh", respectively (Table 3). These results suggested that co-fermentations of the non-Saccharomyces yeast strains and S. cerevisiae exhibited great potential in ethyl esters compounds production in citrus wine.

The content of other esters in Sc-Td co-fermentation was higher than that of other fermentations. These results suggested that different co-fermentations had no regular effects on other esters content.

\subsubsection{Volatile Terpenes, Aldehydes, Ketones, and Phenols}

Major volatile compounds in citrus wine were higher alcohols, esters and fatty acids, but the volatile aldehydes, ketones, terpenes and phenols were also identified. Various types of terpene and aldehyde compound, such as D-limonene, linalool, octanal, and decanal etc. have been reported in citrus juice $[57,58]$. Terpenes are important varietal aroma compounds and can impact on floral aroma of wines [59]. Co-fermentations significantly enhanced the amount and the kinds of terpene compounds in citrus wine $(2.12 \mathrm{mg} / \mathrm{L}-12.98 \mathrm{mg} / \mathrm{L})$ compared with those of pure S. cerevisiae fermentation $(0.00 \mathrm{mg} / \mathrm{L})($ Table 3$)$. The level of terpene compounds was also enhanced in wine and mango wine by non-Saccharomyces yeast strains $[60,61]$. Only D-limonene in Sc-Hu and Sc-Hop fermentations and 1-pentene in Sc-Hop fermentation had the odor activities (Table 2). Aldehydes and ketones were slightly produced in Sc-Hu $(0.56 \mathrm{mg} / \mathrm{L})$ and Sc-Hop $(0.55 \mathrm{mg} / \mathrm{L})$ fermentations, while they were not detected in other fermentations. Only phenylacetaldehyde in Sc-Hu and Sc-Hop fermentation was odor active, and would present on unpleasant green notes [62]. Sc-Td co-fermentation contained higher 
phenol content $(5.20 \mathrm{mg} / \mathrm{L})$ than other fermentations did $(0.00 \mathrm{mg} / \mathrm{L}-0.23 \mathrm{mg} / \mathrm{L})$, and 4-vinyl guaiacol in Sc-Td fermentation was the only odor active phenol compound which would present on coffee, beer, apple aroma (Tables 2 and 3). Different content of terpenes, aldehydes, ketones, and phenols in different fermentations would take on different variety of flavor characteristics in citrus wines and determined by different yeast strains.

\subsection{Principal Component Analysis of Volatile Compounds in Citrus Wine}

The principal component analysis (PCA) demonstrated the correlation and segregation of odor active compounds $(\mathrm{OAV} \geq 1)$ with fermentations (Figure 2). PCA explained $89.7 \%$ of the total variation. The first principal component (PC1) accounted for $54.5 \%$ of the total variation, while PC2 explained $35.2 \%$. Sc-Td co-fermentation significantly clustered with several odor active compounds including ethyl caproate, 1-pentanol, ethyl butyrate, 4-vinyl guaicol and octanoic acid, at the upper right corner, while Sc-Hop and Sc-Hu fermentations grouped together with odor active compounds such as benzene acetaldehyde, 1-pentene, D-limonene and ethyl acetate, at the upper left corner. However, S. cerevisiae fermentation located at the lower right corner with ethyl octanoate and ethyl caprate. Similarly, Zhang et al. indicated that the $S$. cerevisiae monoculture mainly gathered with ethyl octanoate [11]. These results highlighted that different fermentation strategies produced distinctive odor active compounds and would present on different flavor characteristics in citrus wine.

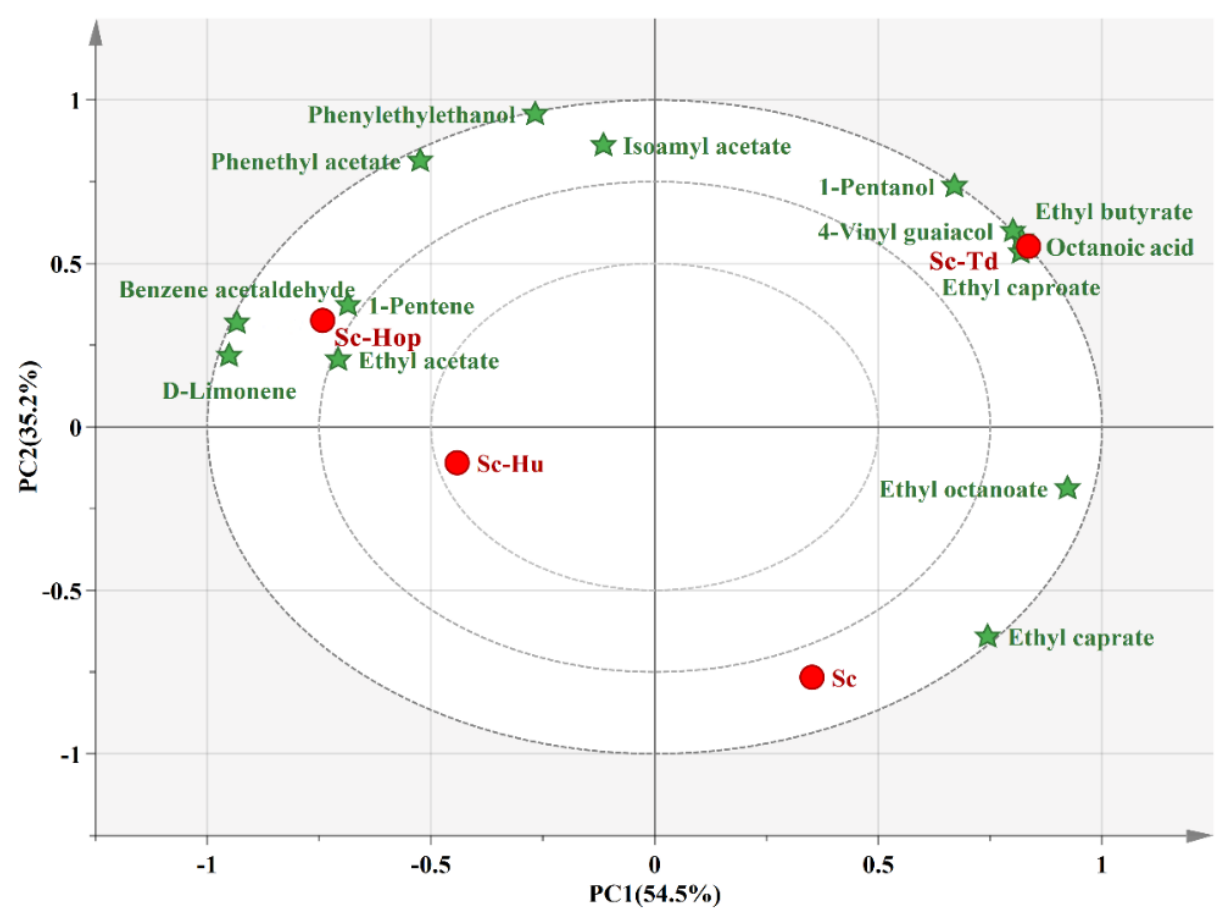

Figure 2. Principal component analysis of volatile aroma compounds in citrus wines. Sc-Hu, S. cerevisiae/H. uvarum co-fermentation; Sc-Td, S. cerevisiae/T. delbrueckii co-fermentation; Sc-Hop, S. cerevisiae/H. opuntiae co-fermentation; Sc, S. cerevisiae fermentation.

\subsection{Hierarchical Cluster Analysis of Volatile Aroma Compounds in Citrus Wine}

Hierarchical cluster analysis was used to differentiate the volatile aroma compound profiles of different fermentations. As revealed in Figure 3, the fermentations were classified into three groups including group of Sc-Td co-fermentation, group of Sc-Hu and Sc-Hop fermentations, and group of Sc fermentation. All the detected volatile compounds from fermentations were clustered into four groups and designated as group I, II, III and IV. Meanwhile, The Sc-Td co-fermentation was rich in volatile aroma compounds of group I (ethyl octanoate and ethyl dodecanoate) and group 
IV (isoamyl acetate, phenylethanol, 3,5-cycloheptatriene, isoamyl formate, ethyl caproate, pentyl octanoate, ethyl butyrate, octanoic acid, 1-pentanol, isolongifolan-8-ol, 2,4-dimethyl-benzoic acid, isopropyl caprylate, ethyl heptanoate, ethyl octadecenoate, pentyl octanoate, propyl 4-phenylbutyrate, pentyl propanate, 1-octene, 1,4-dimethyl-2-vinyl-benzene and 3,4-dimethylphenol). The Sc-Hu and Sc-Hop co-fermentations were abundant in compounds of group II (ethyl acetate, ethyl propionate, 4-methylphenylpropanol, amyl acetate, ethyl cis 4-decenoate, hexyl phenylalanate, 4-ethylbenzoic acid, 2,4-dimethyl-benzoic acid, 4-pentenyl-benzene, D-Limonene and benzenebutanal), and group III (ethyl formate, ethyl undecanoate, ethyl 4-methyl-valerate, amyl formate, 1-pentene and phenylacetaldehyde). However, the volatile compounds from the pure $S$. cerevisiae fermentation belonged to group I (ethyl octanoate, ethyl dodecanoate, ethyl caprate, undecanoic acid, hexanoic acid, dodecanoic acid, and ribitol). These results revealed that different fermentation strategies presented different aroma compound profiles which would take on different flavor complexities and characteristics in citrus wine.

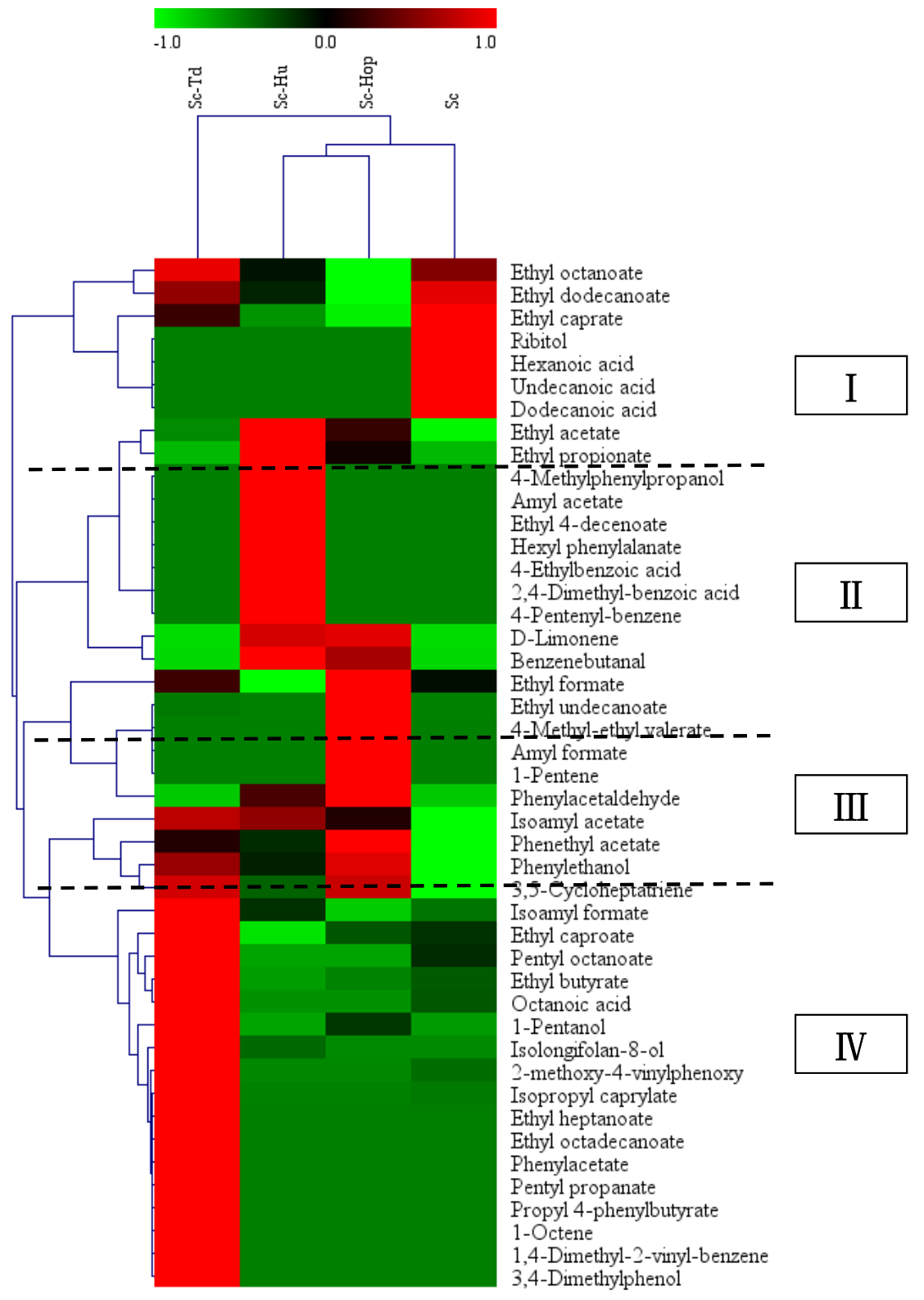

Figure 3. Hierarchical cluster analysis of volatile compounds in citrus wines. Normalization of all values for better visualization; Sc-Hu, S. cerevisiae/H. uvarum co-fermentation; Sc-Td, S. cerevisiae/T. delbrueckii co-fermentation; Sc-Hop, S. cerevisiae/H. opuntiae co-fermentation; Sc, S. cerevisiae fermentation. 


\subsection{Sensory Evaluations of Citrus Wines}

The sensory evaluations of citrus wines were shown in Table 4. Compared with those of pure S. cerevisiae fermentation, the sensory evaluation scores of co-fermentations (13.00-15.00) were higher, and the Sc-Hop co-fermentation received the highest one (15.00), followed by Sc-Hu (14.00) and Sc-Td co-fermentations (13.00). More importantly, the clarity, aroma, taste, taste lasting and overall acceptability of co-fermentations were significantly improved. In detail, aroma and taste of Sc-Hop and Sc-Hu fermentations were greatly improved, followed by Sc-Td fermentations. Meanwhile, the appearance, taste lasting attribute and overall acceptability of co-fermentations were strongly enhanced. Previous researches reported that co-fermentations of non-Saccharomyces yeast strains, such as H. opuntiae, P. kudriavzevii, H. uvarum, T. delbrueckii etc., and S. cerevisiae could improve the fruity, floral, and mouth-feeling of wine [63-65]. Therefore, H. opuntiae, H. uvarum, and T. delbrueckii could be employed to co-ferment with $S$. cerevisiae to improve the sensory quality of citrus wine. The Sc-Hop fermentation was the best method to produce citrus wine with outstanding aroma, taste, taste lasting, and overall acceptability, followed by fermentations of Sc-Hu and Sc-Td, respectively.

Table 4. Sensory evaluation scores of citrus wines.

\begin{tabular}{|c|c|c|c|c|c|c|}
\hline Fermentations & $\begin{array}{c}\text { Clarity } \\
/ 3\end{array}$ & $\begin{array}{c}\text { Aroma (Fruity, } \\
\text { Floral) } \\
/ 6\end{array}$ & $\begin{array}{c}\text { Taste } \\
\text { /6 }\end{array}$ & $\begin{array}{c}\text { Taste } \\
\text { Lasting } \\
\text { /3 }\end{array}$ & $\begin{array}{c}\text { Overall } \\
\text { Acceptability } \\
\text { /2 }\end{array}$ & $\begin{array}{c}\text { Total } \\
/ 20\end{array}$ \\
\hline $\mathrm{Sc}-\mathrm{Hu}$ & $2.83 \pm 0.41 * *$ & $4.16 \pm 0.41^{* *}$ & $3.83 \pm 0.41^{* *}$ & $1.83 \pm 0.41^{* *}$ & $1.33 \pm 0.52 *$ & $14.00 \pm 0.63^{* *}$ \\
\hline Sc-Td & $2.16 \pm 0.41^{* *}$ & $3.67 \pm 0.52^{* *}$ & $3.83 \pm 0.41^{* *}$ & $2.00 \pm 0.00^{* *}$ & $1.33 \pm 0.52 *$ & $13.00 \pm 0.63^{* *}$ \\
\hline Sc-Hop & $2.5 \pm 0.55^{* *}$ & $4.5 \pm 0.55^{* *}$ & $4.33 \pm 0.52 * *$ & $2.00 \pm 0.00^{* *}$ & $1.67 \pm 0.52 * *$ & $15.00 \pm 0.67^{* *}$ \\
\hline $\mathrm{Sc}$ & $1.50 \pm 0.55$ & $2.83 \pm 0.41$ & $2.67 \pm 0.52$ & $1.00 \pm 0.00$ & $1.00 \pm 0.00$ & $9.00 \pm 0.89$ \\
\hline
\end{tabular}

Data show the mean value of the scores from 9 panelists, and the significant differences were with respect to the control Sc. ${ }^{* *} p<0.01 ;{ }^{*} p<0.05$. Sc-Hu, S. cerevisiae/H. uvarum co-fermentation; Sc-Td, S. cerevisiae/T. delbrueckii co-fermentation; Sc-Hop, S. cerevisiae/H. opuntiae co-fermentation; Sc, S. cerevisiae fermentation.

The correlation analysis was employed to study the correlation between sensory evaluation scores and aroma substances. These results showed that the main indicators of sensory evaluation were more significantly related to the esters, terpenes, aldehydes, and ketones $(p<0.01)$ than the other volatile compounds (Table 5). Therefore, the sensory evaluation score of citrus wine was mainly related to the content of ester, terpenes, aldehydes and ketones. Low content of terpenes and aldehydes and ketones also contributed positively to the sensory quality of citrus wine. Generally, many aroma compounds in wine will have a synergistic effect on its flavor, an unbalanced aroma compounds level would have adverse effects on the sensory quality of wine.

In addition, biocontrol strategies for the limitation of undesired microbial growth in foods and beverages by the application of non-Saccharomyces yeasts have been highlighted in recent years [66,67]. Berbegal et al. [68] reported that the use of a mixed starter of different strains of $S$. cerevisiae or a mix of specific strains of non-Saccharomyces yeast with $S$. cerevisiae are efficient strategies in the control of the spoilage yeast like Brettanomyces bruxellensis and the volatile phenols' production in wine. Interestingly, the inoculation of different non-Saccharomyces and the inoculation time of the non-Saccharomyces yeast with respect to $S$. cerevisiae resources (co-inoculated and sequentially inoculated) influence the composition of the connected malolactic fermentation consortia, modulating malolactic fermentation performance [69]. 
Table 5. Correlation analysis between sensory evaluation scores and aroma compounds.

\begin{tabular}{ccccccc}
\hline Compounds Categories & Clarity & Aroma & Taste & $\begin{array}{c}\text { Taste } \\
\text { Lasting }\end{array}$ & Acceptability & Total \\
\hline Higher alcohols & 0.307 & 0.333 & 0.518 & $\mathbf{0 . 7 5 1} * *$ & 0.305 & 0.469 \\
Total esters & $\mathbf{0 . 8 6 1 * *}$ & $\mathbf{0 . 8 6 3 * *}$ & $\mathbf{0 . 9 4} * *$ & $\mathbf{0 . 9 2 8} * *$ & $\mathbf{0 . 7 9 5 *}$ & $\mathbf{0 . 9 5 2} * *$ \\
Fatty acids & -0.196 & -0.265 & -0.087 & -0.217 & -0.246 & -0.141 \\
Terpenes & 0.561 & $\mathbf{0 . 6 6} *$ & $\mathbf{0 . 7 9 2} * *$ & $\mathbf{0 . 8 4} * *$ & $\mathbf{0 . 6 4 2} *$ & $\mathbf{0 . 7 5 4} * *$ \\
Aldehydes and ketones & $\mathbf{0 . 7 0 9 *}$ & $\mathbf{0 . 7 4 8 * *}$ & $\mathbf{0 . 7 6 9 *}$ & 0.57 & $\mathbf{0 . 7 7 5 * *}$ & $\mathbf{0 . 7 7 8} * *$ \\
Phenols & -0.128 & -0.194 & -0.01 & 0.293 & -0.18 & -0.064 \\
\hline
\end{tabular}

Bold value indicated significant different, and ${ }^{*}, * *$ indicated significant difference at $5 \%$ and $1 \%$, respectively.

\section{Conclusions}

The selected non-Saccharomyces yeast strains and S. cerevisiae could grow normally during their co-fermentations with the exception of H. uvarum, which was inhibited by S. cerevisiae, and produced citrus wines with low amount of ethanol and total acidity, and high residual sugar content and $\mathrm{pH}$ value, and with no significant difference in volatile acid concentration compared with those of S. cerevisiae fermentation. The co-fermentations produced citrus wine with higher content of volatile aroma compounds, especially higher alcohols and esters, than pure S. cerevisiae fermentation did. However, they had no regular effects on the content of fatty acids, terpenes, aldehydes, ketones, and phenols. At the same time, different fermentations including co-fermentations and pure fermentation, produced different aroma compound profiles, and odor active compound profiles, and would present on different flavor complexities and characteristics in citrus wines. More importantly, all the co-fermentations could improve the sensory quality of citrus wine, Sc-Hop co-fermentation produced the best sensory quality of citrus wine, followed by Sc-Hu and Sc-Td co-fermentations. All the results indicated these co-fermentations, producing high content of volatile aroma compounds, especially higher alcohols and esters, benefitted the sensory quality improvement of citrus wine. However, the mechanism that co-fermentation can increase the content of higher alcohols in citrus wine is not known.

Author Contributions: Conceptualization and methodology, X.Z. and X.W.; Software and formal analysis, R.L.; Writing-original draft preparation, L.H.; writing-review and editing, X.Z. and L.H. All authors have read and agreed to the published version of the manuscript.

Funding: This research was funded by the National Natural Science Foundation Project of China (31871768) and the Major Science and Technology Program of Ningxia Hui Autonomous Region (2016BZ0601/02/03).

Conflicts of Interest: There are no conflicts of interest among the authors.

\section{References}

1. Azam, M.; Song, M.; Fan, F.; Zhang, B.; Xu, Y.; Xu, C.; Chen, K. Comparative analysis of flower volatiles from nine citrus at three blooming stages. Int. J. Mol. Sci. 2013, 14, 22346-22367. [CrossRef]

2. Gao, Y.; Kan, C.; Chen, M.; Chen, C.; Chen, Y.; Fu, Y.; Wan, C.; Chen, J. Effects of Chitosan-Based Coatings Enriched with Cinnamaldehyde on Mandarin Fruit cv. Ponkan during Room-Temperature Storage. Coatings 2018, 8, 372. [CrossRef]

3. Zhong, Y.; Cheng, C.; Jiang, B.; Jiang, N.; Zhang, Y.; Hu, M.; Zhong, G. Digital gene expression analysis of Ponkan mandarin (Citrus reticulata Blanco) in response to Asia citrus psyllid-vectored Huanglongbing infection. Int. J. Mol. Sci. 2016, 17, 1063. [CrossRef] [PubMed]

4. Selli, S.; Canbas, A.; Varlet, V.; Kelebek, H.; Prost, C.; Serot, T. Characterization of the most odor-active volatiles of orange wine made from a Turkish cv. Kozan (Citrus sinensis L. Osbeck). J. Agric. Food Chem. 2007, 56, 227-234. [CrossRef] [PubMed]

5. Liu, R.; Zhang, Q.; Chen, F.; Zhang, X. Analysis of culturable yeast diversity in spontaneously fermented orange wine, orange peel and orangery soil of a Ponkan plantation in China. Ann. Microbiol. 2015, 65, 2387-2391. [CrossRef] 
6. Albergaria, H.; Arneborg, N. Dominance of Saccharomyces cerevisiae in alcoholic fermentation processes: Role of physiological fitness and microbial interactions. Appl. Microbiol. Biotechnol. 2016, 100, 2035-2046. [CrossRef]

7. Liu, P.-T.; Lu, L.; Duan, C.-Q.; Yan, G.-L. The contribution of indigenous non-Saccharomyces wine yeast to improved aromatic quality of Cabernet Sauvignon wines by spontaneous fermentation. LWT Food Sci. Technol. 2016, 71, 356-363. [CrossRef]

8. Lencioni, L.; Romani, C.; Gobbi, M.; Comitini, F.; Ciani, M.; Domizio, P. Controlled mixed fermentation at winery scale using Zygotorulaspora florentina and Saccharomyces cerevisiae. Int. J. Food Microbiol. 2016, 234, 36-44. [CrossRef]

9. Petruzzi, L.; Capozzi, V.; Berbegal, C.; Corbo, M.R.; Bevilacqua, A.; Spano, G.; Sinigaglia, M. Microbial resources and enological significance: Opportunities and benefits. Front. Microbiol. 2017, 8, 995. [CrossRef]

10. Englezos, V.; Torchio, F.; Cravero, F.; Marengo, F.; Giacosa, S.; Gerbi, V.; Rantsiou, K.; Rolle, L.; Cocolin, L. Aroma profile and composition of Barbera wines obtained by mixed fermentations of Starmerella bacillaris (synonym Candida zemplinina) and Saccharomyces cerevisiae. LWT Food Sci. Technol. 2016, 73, 567-575. [CrossRef]

11. Zhang, B.Q.; Shen, J.Y.; Duan, C.Q.; Yan, G.L. Use of Indigenous Hanseniaspora vineae and Metschnikowia pulcherrima co-fermentation with Saccharomyces cerevisiae to improve the aroma diversity of Vidal Blanc Icewine. Front. Microbiol. 2018, 9, 2303. [CrossRef]

12. Benito, S.; Hofmann, T.; Laier, M.; Lochbühler, B.; Schüttler, A.; Ebert, K.; Fritsch, S.; Röcker, J.; Rauhut, D. Effect on quality and composition of riesling wines fermented by sequential inoculation with non-Saccharomyces and Saccharomyces cerevisiae. Eur. Food Res. Technol. 2015, 241, 707-717. [CrossRef]

13. Benito, Á.; Calderón, F.; Benito, S. The Influence of Non-Saccharomyces Species on Wine Fermentation Quality Parameters. Fermentation 2019, 5, 54. [CrossRef]

14. Mateus, D.; Sousa, S.; Coimbra, C.; Rogerson, F.S.; Simões, J. Identification and Characterization of Non-Saccharomyces Species Isolated from Port Wine Spontaneous Fermentations. Foods 2020, 9, 120. [CrossRef] [PubMed]

15. Oliveira, I.; Ferreira, V. Modulating Fermentative, Varietal and Aging Aromas of Wine Using non-Saccharomyces Yeasts in a Sequential Inoculation Approach. Microorganisms 2019, 7, 164. [CrossRef] [PubMed]

16. Comitini, F.; Gobbi, M.; Domizio, P.; Romani, C.; Lencioni, L.; Mannazzu, I.; Ciani, M. Selected non-Saccharomyces wine yeasts in controlled multistarter fermentations with Saccharomyces cerevisiae. Food Microbiol. 2011, 28, 873-882. [CrossRef]

17. Ciani, M.; Comitini, F.; Mannazzu, I.; Domizio, P. Controlled mixed culture fermentation: A new perspective on the use of non-Saccharomyces yeasts in winemaking. FEMS Yeast Res. 2010, 10, 123-133. [CrossRef]

18. Malfeito-Ferreira, M. Two decades of "horse sweat" taint and Brettanomyces yeasts in wine: Where do we stand now? Beverages 2018, 4, 32. [CrossRef]

19. Merín, M.G.; Vi, M.D.A. Highly cold-active pectinases under wine-like conditions from non-Saccharomyces yeasts for enzymatic production during winemaking. Lett. Appl. Microbiol. 2015, 60, 467-474. [CrossRef]

20. Capozzi, V.; Di Toro, M.R.; Grieco, F.; Michelotti, V.; Salma, M.; Lamontanara, A.; Russo, P.; Orrù, L.; Alexandre, H.; Spano, G. Viable But Not Culturable (VBNC) state of Brettanomyces bruxellensis in wine: New insights on molecular basis of VBNC behaviour using a transcriptomic approach. Food Microbiol. 2016, 59, 196-204. [CrossRef]

21. Roca-Mesa, H.; Sendra, S.; Mas, A.; Beltran, G.; Torija, M.-J. Nitrogen Preferences during Alcoholic Fermentation of Different Non-Saccharomyces Yeasts of Oenological Interest. Microorganisms 2020, 8, 157. [CrossRef] [PubMed]

22. Von Cosmos, N.H.; Edwards, C.G. Use of nutritional requirements for Brettanomyces bruxellensis to limit infections in wine. Fermentation 2016, 2, 17. [CrossRef]

23. Berbegal, C.; Spano, G.; Tristezza, M.; Grieco, F.; Capozzi, V. Microbial resources and innovation in the wine production sector. S. Afr. J. Enol. Vitic. 2017, 38, 156-166. [CrossRef]

24. Hu, L.; Jia, W.; Ji, X.; Rui, L.; Chen, F.; Zhang, X. Selection of non-Saccharomyces yeasts for orange wine fermentation based on their enological traits and volatile compounds formation. J. Food Sci. Technol. 2018, 55, 4001-4012. [CrossRef] 
25. Pallmann, C.L.; Brown, J.A.; Olineka, T.L.; Cocolin, L.; Mills, D.A.; Bisson, L.F. Use of WL medium to profile native flora fermentations. Am. J. Enol. Vitic. 2001, 52, 198-203.

26. Grosch, W. Evaluation of the key odorants of foods by dilution experiments, aroma models and omission. Chem. Senses 2001, 26, 533-545. [CrossRef]

27. Wang, C.; Mas, A.; Esteve-Zarzoso, B. Interaction between Hanseniaspora uvarum and Saccharomyces cerevisiae during alcoholic fermentation. Int. J. Food Microbiol. 2015, 206, 67-74. [CrossRef]

28. Tristezza, M.; Tufariello, M.; Capozzi, V.; Spano, G.; Mita, G.; Grieco, F. The oenological potential of Hanseniaspora uvarumin simultaneous and sequential co-fermentation with Saccharomyces cerevisiae for industrial wine production. Front. Microbiol. 2016, 7, 670. [CrossRef]

29. Kemsawasd, V.; Branco, P.; Almeida, M.G.; Caldeira, J.; Albergaria, H.; Arneborg, N. Cell-to-cell contact and antimicrobial peptides play a combined role in the death of Lachanchea thermotolerans during mixed-culture alcoholic fermentation with Saccharomyces cerevisiae. FEMS Microbiol. Lett. 2015, 362, fnv103. [CrossRef]

30. Belda, I.; Navascués, E.; Marquina, D.; Santos, A.; Calderon, F.; Benito, S. Dynamic analysis of physiological properties of Torulaspora delbrueckii in wine fermentations and its incidence on wine quality. Appl. Microbiol. Biotechnol. 2015, 99, 1911-1922. [CrossRef]

31. Branco, P.; Francisco, D.; Monteiro, M.; Almeida, M.G.; Caldeira, J.; Arneborg, N.; Prista, C.; Albergaria, H. Antimicrobial properties and death-inducing mechanisms of saccharomycin, a biocide secreted by Saccharomyces cerevisiae. Appl. Microbiol. Biotechnol. 2017, 101, 159-171. [CrossRef] [PubMed]

32. Liu, S.; Laaksonen, O.; Kortesniemi, M.; Kalpio, M.; Yang, B. Chemical composition of bilberry wine fermented with non-Saccharomyces yeasts (Torulaspora delbrueckii and Schizosaccharomyces pombe) and Saccharomyces cerevisiae in pure, sequential and mixed fermentations. Food Chem. 2018, 266, 262-274. [CrossRef]

33. Sun, S.Y.; Gong, H.S.; Jiang, X.M.; Zhao, Y.P. Selected non-Saccharomyces wine yeasts in controlled multistarter fermentations with Saccharomyces cerevisiae on alcoholic fermentation behaviour and wine aroma of cherry wines. Food Microbiol. 2014, 44, 15-23. [CrossRef] [PubMed]

34. Cameleyre, M.; Lytra, G.; Tempere, S.; Barbe, J.C. Olfactory impact of higher alcohols on red wine fruity ester aroma expression in model solution. J. Agric. Food Chem. 2015, 63, 9777-9788. [CrossRef] [PubMed]

35. Querol, A.; Fleet, G.H. Yeasts in Food and Beverages; Springer: Berlin, Germany, 2006; pp. 31-32.

36. Liu, S.; Laaksonen, O.; Yang, B. Volatile composition of bilberry wines fermented with non-Saccharomyces and Saccharomyces yeasts in pure, sequential and simultaneous inoculations. Food Microbiol. 2019, 80, $25-39$. [CrossRef] [PubMed]

37. Escribano-Viana, R.; González-Arenzana, L.; Portu, J.; Garijo, P.; López-Alfaro, I.; López, R.; Santamaría, P.; Gutiérrez, A.R. Wine aroma evolution throughout alcoholic fermentation sequentially inoculated with non-Saccharomyces/Saccharomyces yeasts. Food Res. Int. 2018, 112, 17-24. [CrossRef]

38. Romano, P.; Suzzi, G. Higher alcohol and acetoin production by Zygosaccharomyces wine yest. J. Appl. Microbiol. 2008, 75, 541-545.

39. Varela, C.; Sengler, F.; Solomon, M.; Curtin, C. Volatile flavour profile of reduced alcohol wines fermented with the non-conventional yeast species Metschnikowia pulcherrima and Saccharomyces uvarum. Food Chem. 2016, 209, 57-64. [CrossRef]

40. Wang, C.; Mas, A.; Esteve-Zarzoso, B. The interaction between Saccharomyces cerevisiae and non-Saccharomyces yeast during alcoholic fermentation is species and strain specific. Front. Microbiol. 2016, 7, 502. [CrossRef]

41. Liu, N.; Qin, Y.; Song, Y.; Ye, D.; Yuan, W.; Pei, Y.; Xue, B.; Liu, Y. Selection of indigenous Saccharomyces cerevisiae strains in Shanshan County (Xinjiang, China) for winemaking and their aroma-producing characteristics. World J. Microbiol. Biotechnol. 2015, 31, 1781-1792. [CrossRef]

42. Peng, C.-T.; Wen, Y.; Tao, Y.-S.; Lan, Y.-Y. Modulating the formation of Meili wine aroma by prefermentative freezing process. J. Agric. Food Chem. 2013, 61, 1542-1553. [CrossRef] [PubMed]

43. Ferreira, V.; Lopez, R.; Cacho, J.F. Quantitative determination of the odorants of young red wines from different grape varieties. J. Sci. Food Agric. 2000, 80, 1659-1667. [CrossRef]

44. Guth, H. Quantitation and sensory studies of character impact odorants of different white wine varieties. J. Agric. Food Chem. 1997, 45, 3027-3032. [CrossRef]

45. Fan, W.; Xu, Y.; Jiang, W.; Li, J. Identification and quantification of impact aroma compounds in 4 nonfloral Vitis vinifera varieties grapes. J. Food Sci. 2010, 75, S81-S88. [CrossRef] [PubMed] 
46. Culleré, L.; Escudero, A.; Cacho, J.; Ferreira, V. Gas chromatography-olfactometry and chemical quantitative study of the aroma of six premium quality Spanish aged red wines. J. Agric. Food Chem. 2004, 52, 1653-1660. [CrossRef]

47. Saerens, S.M.; Verstrepen, K.J.; Van Laere, S.D.; Voet, A.R.; Van Dijck, P.; Delvaux, F.R.; Thevelein, J.M. The Saccharomyces cerevisiae EHT1 and EEB1 genes encode novel enzymes with medium-chain fatty acid ethyl ester synthesis and hydrolysis capacity. J. Biol. Chem. 2006, 281, 4446-4456. [CrossRef]

48. San-Juan, F.; Ferreira, V.; Cacho, J.; Escudero, A. Quality and aromatic sensory descriptors (mainly fresh and dry fruit character) of Spanish red wines can be predicted from their aroma-active chemical composition. $J$. Agric. Food Chem. 2011, 59, 7916-7924. [CrossRef]

49. Noguerol-Pato, R.; González-Álvarez, M.; González-Barreiro, C.; Cancho-Grande, B.; Simal-Gándara, J. Aroma profile of Garnacha Tintorera-based sweet wines by chromatographic and sensorial analyses. Food Chem. 2012, 134, 2313-2325. [CrossRef]

50. Azzolini, M.; Fedrizzi, B.; Tosi, E.; Finato, F.; Vagnoli, P.; Scrinzi, C.; Zapparoli, G. Effects of Torulaspora delbrueckii and Saccharomyces cerevisiae mixed cultures on fermentation and aroma of Amarone wine. Eur. Food Res. Technol. 2012, 235, 303-313. [CrossRef]

51. Verstrepen, K.J.; Derdelinckx, G.; Dufour, J.-P.; Winderickx, J.; Thevelein, J.M.; Pretorius, I.S.; Delvaux, F.R. Flavor-active esters: Adding fruitiness to beer. J. Biosci. Bioeng. 2003, 96, 110-118. [CrossRef]

52. Mingorance-Cazorla, L.; Clemente-Jiménez, J.; Martínez-Rodríguez, S.; Las Heras-Vázquez, F.; Rodríguez-Vico, F. Contribution of different natural yeasts to the aroma of two alcoholic beverages. World J. Microbiol. Biotechnol. 2003, 19, 297-304. [CrossRef]

53. Moreira, N.; Mendes, F.; de Pinho, P.G.; Hogg, T.; Vasconcelos, I. Heavy sulphur compounds, higher alcohols and esters production profile of Hanseniaspora uvarum and Hanseniaspora guilliermondii grown as pure and mixed cultures in grape must. Int. J. Food Microbiol. 2008, 124, 231-238. [CrossRef] [PubMed]

54. Rojas, V.; Gil, J.V.; Piñaga, F.; Manzanares, P. Acetate ester formation in wine by mixed cultures in laboratory fermentations. Int. J. Food Microbiol. 2003, 86, 181-188. [CrossRef]

55. Hu, K.; Jin, G.J.; Mei, W.C.; Li, T.; Tao, Y.S. Increase of medium-chain fatty acid ethyl ester content in mixed H. uvarum/S. cerevisiae fermentation leads to wine fruity aroma enhancement. Food Chem. 2018, 239, 495-501. [CrossRef] [PubMed]

56. Gao, P.; Xia, W.; Li, X.; Liu, S.Q. Use of wine and dairy yeasts as single starter cultures for flavor compound modification in fish sauce fermentation. Front. Microbiol. 2019, 10, 2300. [CrossRef]

57. Komthong, P.; Katoh, T.; Igura, N.; Shimoda, M.; Hayakawa, I. Ascending bubble extraction of terpenes from freshly squeezed orange juice. Food Res. Int. 2006, 39, 53-58. [CrossRef]

58. Plotto, A.; Margaría, C.A.; Goodner, K.L.; Goodrich, R.; Baldwin, E.A. Odour and flavour thresholds for key aroma components in an orange juice matrix: Terpenes and aldehydes. Flavour Fragr. J. 2004, 19, 491-498. [CrossRef]

59. Weldegergis, B.T.; de Villiers, A.; McNeish, C.; Seethapathy, S.; Mostafa, A.; Górecki, T.; Crouch, A.M. Characterisation of volatile components of Pinotage wines using comprehensive two-dimensional gas chromatography coupled to time-of-flight mass spectrometry (GC× GC-TOFMS). Food Chem. 2011, 129, 188-199. [CrossRef]

60. Renault, P.; Miot-Sertier, C.; Marullo, P.; Hernández-Orte, P.; Lagarrigue, L.; Lonvaud-Funel, A.; Bely, M. Genetic characterization and phenotypic variability in Torulaspora delbrueckii species: Potential applications in the wine industry. Int. J. Food Microbiol. 2009, 134, 201-210. [CrossRef]

61. Sadineni, V.; Kondapalli, N.; Obulam, V.S.R. Effect of co-fermentation with Saccharomyces cerevisiae and Torulaspora delbrueckii or Metschnikowia pulcherrima on the aroma and sensory properties of mango wine. Ann. Microbiol. 2012, 62, 1353-1360. [CrossRef]

62. Yang, H.; Wu, D.; Guo, D.; Lu, J. The aromatic volatile composition of Lonicera edulis wines produced with three different strains of Saccharomyces cerevisiae. J. Inst. Brew. 2019, 125, 100-109. [CrossRef]

63. Luan, Y.; Zhang, B.; Duan, C.; Yan, G. Effects of different pre-fermentation cold maceration time on aroma compounds of Saccharomyces cerevisiae co-fermentation with Hanseniaspora opuntiae or Pichia kudriavzevii. LWT Food Sci. Technol. 2018, 92, 177-186. [CrossRef]

64. Kim, D.H.; Hong, Y.A.; Park, H.D. Co-fermentation of grape must by Issatchenkia orientalis and Saccharomyces cerevisiae reduces the malic acid content in wine. Biotechnol. Lett. 2008, 30, 1633-1638. [CrossRef] [PubMed] 
65. Renault, P.; Coulon, J.; Revel, G.D.; Barbe, J.C.; Bely, M. Increase of fruity aroma during mixed T. delbrueckii/S. cerevisiae wine fermentation is linked to specific esters enhancement. Int. J. Food Microbiol. 2015, 207, 40-48. [CrossRef]

66. Kuchen, B.; Maturano, Y.P.; Mestre, M.V.; Combina, M.; Toro, M.E.; Vazquez, F. Selection of native non-Saccharomyces yeasts with biocontrol activity against spoilage yeasts in order to produce healthy regional wines. Fermentation 2019, 5, 60. [CrossRef]

67. Berbegal, C.; Garofalo, C.; Russo, P.; Pati, S.; Capozzi, V.; Spano, G. Use of autochthonous yeasts and bacteria in order to control Brettanomyces bruxellensis in wine. Fermentation 2017, 3, 65. [CrossRef]

68. Berbegal, C.; Spano, G.; Fragasso, M.; Grieco, F.; Russo, P.; Capozzi, V. Starter cultures as biocontrol strategy to prevent Brettanomyces bruxellensis proliferation in wine. Appl. Microbiol. Biotechnol. 2018, 102, 569-576. [CrossRef]

69. Berbegal, C.; Borruso, L.; Fragasso, M.; Tufariello, M.; Russo, P.; Brusetti, L.; Spano, G.; Capozzi, V. A metagenomic-based approach for the characterization of bacterial diversity associated with spontaneous malolactic fermentations in wine. Int. J. Mol. Sci. 2019, 20, 3980. [CrossRef]

(C) 2020 by the authors. Licensee MDPI, Basel, Switzerland. This article is an open access article distributed under the terms and conditions of the Creative Commons Attribution (CC BY) license (http://creativecommons.org/licenses/by/4.0/). 